\title{
Spontaneous vesicle recycling in the synaptic bouton
}

\author{
Sven Truckenbrodt ${ }^{1,2 *}$ and Silvio O. Rizzoli ${ }^{1 *}$ \\ Department of Neuro- and Sensory Physiology, University of Göttingen Medical Center, European Neuroscience Institute, Cluster of Excellence Nanoscale \\ Microscopy and Molecular Physiology of the Brain, Göttingen, Germany \\ 2 International Max Planck Research School for Molecular Biology, Göttingen, Germany
}

\author{
Edited by: \\ Hartmut Schmidt, University of \\ Leipzig, Germany \\ Reviewed by: \\ Annalisa Scimemi, SUNY Albany, \\ USA \\ Pascal Kaeser, Harvard Medical \\ School, USA

\section{*Correspondence:} \\ Sven Truckenbrodt and Silvio 0. \\ Rizzoli, Department of Neuro- and \\ Sensory Physiology, University of \\ Göttingen Medical Center, \\ Humboldtallee 23, 37073 Göttingen, \\ Germany \\ e-mail: strucke@gwdg.de; \\ srizzol@gwdg.de
}

The trigger for synaptic vesicle exocytosis is $\mathrm{Ca}^{2+}$, which enters the synaptic bouton following action potential stimulation. However, spontaneous release of neurotransmitter also occurs in the absence of stimulation in virtually all synaptic boutons. It has long been thought that this represents exocytosis driven by fluctuations in local $\mathrm{Ca}^{2+}$ levels. The vesicles responding to these fluctuations are thought to be the same ones that release upon stimulation, albeit potentially triggered by different $\mathrm{Ca}^{2+}$ sensors. This view has been challenged by several recent works, which have suggested that spontaneous release is driven by a separate pool of synaptic vesicles. Numerous articles appeared during the last few years in support of each of these hypotheses, and it has been challenging to bring them into accord. We speculate here on the origins of this controversy, and propose a solution that is related to developmental effects. Constitutive membrane traffic, needed for the biogenesis of vesicles and synapses, is responsible for high levels of spontaneous membrane fusion in young neurons, probably independent of $\mathrm{Ca}^{2+}$. The vesicles releasing spontaneously in such neurons are not related to other synaptic vesicle pools and may represent constitutively releasing vesicles (CRVs) rather than bona fide synaptic vesicles. In mature neurons, constitutive traffic is much dampened, and the few remaining spontaneous release events probably represent bona fide spontaneously releasing synaptic vesicles (SRSVs) responding to $\mathrm{Ca}^{2+}$ fluctuations, along with a handful of $C R V s$ that participate in synaptic vesicle turnover.

Keywords: spontaneous release, synaptic vesicle recycling, synaptic vesicle pools, synaptic vesicle biogenesis, synapse development

\section{INTRODUCTION: THE PHENOMENON OF SPONTANEOUS RELEASE AT THE SYNAPTIC BOUTON}

Neuronal communication relies on precisely timed synaptic vesicle exocytosis, which is typically triggered by a brief intracellular $\mathrm{Ca}^{2+}$ spike that follows action potentials (Südhof, 2004; Rizzoli, 2014). However, in parallel to stimulated release, all synapses also display spontaneous release of neurotransmitter. This phenomenon has been observed very early on in the history of research in synaptic communication, starting with several landmark papers quantifying synaptic release under physiological conditions, and typically occurs at very low rates of less than $0.1 \mathrm{~Hz}$ (Fatt and Katz, 1950, 1952; Del Castillo and Katz, 1954). This type of release did not receive significant further attention until recently (see reviews by Ramirez and Kavalali, 2011; Andreae and Burrone, 2014; Kaeser and Regehr, 2014; Rizzoli, 2014). The main difference between these two modes of release is that stimulated release is directly coupled to action potentials, while spontaneous release can occur seemingly without any trigger, at any time. Spontaneous release can be increased experimentally, by $\mathrm{Ca}^{2+}$-dependent mechanisms, such as caffeine triggered $\mathrm{Ca}^{2+}$ release from internal stores (Zefirov et al., 2006), as well as by $\mathrm{Ca}^{2+}$-independent mechanisms, including application of lanthanum ions (Heuser and Miledi, 1971), of black widow spider venom, whose main active component is alpha-latrotoxin (Ceccarelli et al., 1972, 1973; Betz and Henkel, 1994), or hyperosmotic sucrose (Rosenmund and Stevens, 1996).

We give here an overview of the phenomenon of spontaneous release, briefly reviewing some of the available evidence on its $\mathrm{Ca}^{2+}$ dependency. We then focus on the intense recent debate on whether active and spontaneous release originate from the same pool of vesicles. We suggest a simple solution to this problem: two completely different pools of vesicles share the synaptic bouton-synaptic vesicles, which can respond to stimulation but also act as spontaneously releasing synaptic vesicles (SRSVs) and constitutively releasing vesicles (CRVs), which are involved in constitutive membrane traffic and which are not responsive to stimulation. The prevailing view that we are following in this review is that exocytosis of synaptic vesicles is mainly $\mathrm{Ca}^{2+}$. dependent, either in response to action potentials or following spontaneous $\mathrm{Ca}^{2+}$ fluctuations. The CRVs only exocytose spontaneously, and may be completely independent of $\mathrm{Ca}^{2+}$. Finally, we show that this hypothesis is in agreement with the potential roles for spontaneously releasing vesicles throughout neuronal development.

\section{THE CALCIUM SENSORS FOR SPONTANEOUS RELEASE}

As indicated above, there are many ways in which spontaneous release can be elicited from synaptic terminals. The machinery 
for synaptic vesicle release is clearly prone to release even in the absence of action potentials, and even in the absence of $\mathrm{Ca}^{2+}$, both external and internal (Rizzoli and Betz, 2002). Whether physiological spontaneous release is $\mathrm{Ca}^{2+}$-dependent has been a matter of debate, and has triggered the search for a specific $\mathrm{Ca}^{2+}$ sensor. Synaptotagmin 1 has been recognized as the major $\mathrm{Ca}^{2+}$ sensor for mediating synaptic release, but mainly in the context of stimulation (Geppert et al., 1994; Südhof, 2004). However, synaptotagmin 1 has also been proposed to facilitate spontaneous release: knock-ins with enhanced apparent $\mathrm{Ca}^{2+}$ affinity increased spontaneous release, while knock-ins with reduced apparent $\mathrm{Ca}^{2+}$ affinity decreased spontaneous release (Xu et al., 2009; but also see Littleton et al., 1993). This is in agreement with the hypothesis that physiological spontaneous release is caused by spontaneous $\mathrm{Ca}^{2+}$ fluctuations. Paradoxically, however, the knock-out of synaptotagmin 1 does lead to a severe increase in spontaneous release (Xu et al., 2009), suggesting that alternative $\mathrm{Ca}^{2+}$ sensors must also play a role in this process. The cytoplasmic high-affinity $\mathrm{Ca}^{2+}$ binding protein Doc $2 \mathrm{~b}$ has instead been proposed as a specialized sensor for spontaneous release (Groffen et al., 2006, 2010). The knock-out of Doc2b leads to a severe decrease in spontaneous release, but leaves stimulated release unaltered (Groffen et al., 2010). Mechanistically, the higher affinity for $\mathrm{Ca}^{2+}$ of Doc2b could make it responsive to small fluctuations in local $\mathrm{Ca}^{2+}$ levels that would be subthreshold for the facilitation of release via synaptotagmin 1 , an effect that is mimicked by synaptotagmin 1 mutants with high affinity for $\mathrm{Ca}^{2+}$ (Xu et al., 2009). Such local $\mathrm{Ca}^{2+}$ fluctuations might, however, also be high enough to trigger release via activation of synapotagmin 1 , and Doc $2 b$ might play a different role in spontaneous release, since a $\mathrm{Ca}^{2+}$ binding deficient Doc2b mutant restored spontaneous release in knock-downs (Pang et al., 2011).

\section{DIFFERENT VIEWS ON THE SPONTANEOUS POOL OF SYNAPTIC VESICLES}

The association of the soluble protein Doc2b with the vesicles containing synaptotagmin 1 would render them prone to both spontaneous and stimulated release (see also Walter et al., 2011). Alternatively, vesicles containing only one of these molecules would release only spontaneously, or only during stimulation. Whether the sensor molecules are present on all vesicles is currently unknown. Their large copy numbers, however (about 15 synaptotagmin 1, and about 10 Doc2 molecules per vesicle, on average; Takamori et al., 2006; Wilhelm et al., 2014), make it probable that most of the bona fide synaptic vesicles are associated with at least a few copies of both.

The debate of whether spontaneous release occurs from the same pool of synaptic vesicles as stimulated release has been complicated by many conflicting data published in recent years (for example, Sara et al., 2005; Groemer and Klingauf, 2007; Mathew et al., 2008; Fredj and Burrone, 2009; Wilhelm et al., 2010). Spontaneous recycling has been recently investigated in neuronal cultures by silencing stimulated activity with tetrodotoxin (TTX), which abolishes action potentials. Under these conditions, synaptic vesicles participating in spontaneous release and recycling can be selectively loaded with membrane dyes, such as the FM dyes.
After washing out the dye, the exocytosis of the FM-loaded vesicles can be monitored by measuring the loss of fluorescence, as the dye is released from the vesicles into the bathing fluid (see Figure 1).

This type of experiment has initially suggested that vesicles loaded with dye under spontaneous conditions could not be induced to unload by stimulation, and, conversely, that synaptic vesicles loaded with dye during stimulation were not released spontaneously, in TTX (Sara et al., 2005). These observations were later verified by further FM dye experiments (Mathew et al., 2008; Chung et al., 2010). Surprisingly, other groups performed the same experiments, under comparable conditions, and found the opposite: namely that the same vesicles could recycle both under spontaneous and stimulated conditions (Groemer and Klingauf, 2007; Wilhelm et al., 2010).

One possible explanation for this controversy was that the FM dye experiments were difficult to analyse, and that the conclusions depended strongly on the methods used for quantification and normalization (Groemer and Klingauf, 2007). Several other types of labeling were therefore employed, ranging from the enzymatic coupling of biotin to synaptic vesicle proteins, to be later detected by fluorophore-coupled streptavidin (Fredj and Burrone, 2009), to synaptotagmin 1 labeling by antibodies recognizing its intravesicular tail (Hua et al., 2010; Wilhelm et al., 2010). These experiments served to deepen the controversy, by providing evidence both for a separate vesicle pool driving spontaneous release (Fredj and Burrone, 2009), and for the opposite, two independent pools (Hua et al., 2010; Wilhelm et al., 2010).

\section{THE ROLE OF SPONTANEOUS RELEASE DURING DEVELOPMENT SUGGESTS A SIMPLE SOLUTION FOR THE PROBLEM OF THE SPONTANEOUS POOL}

How can these conflicting results be reconciled? The key to understanding spontaneous release may lie in its likely role in synaptic biology. Spontaneous release has often been dismissed as a purely stochastic phenomenon, an accidental fusion of synaptic vesicles which should normally only fuse in response to a stimulus. This view is probably incorrect. The machinery of synaptic release has evolved to restrict accidental release of neurotransmitter, with various levels of fail-safe mechanisms to prevent accidental fusion (Jahn and Fasshauer, 2012; Südhof, 2013). At the same time, there is mounting evidence that spontaneous release is far from useless to the neuron, and that it actually has a crucial role in synapse biogenesis, maturation, and maintenance (McKinney et al., 1999; Saitoe et al., 2001; Sutton et al., 2006; Choi et al., 2014; Kaeser and Regehr, 2014).

First of all, we need to consider how synapses and synaptic vesicles are formed. The establishment of synapses entails the transport of various building blocks (for the active zone, the cytoskeleton, synaptic vesicles, and cell-cell adhesion complexes) from the cell soma to the site of the newly forming synapse. These building blocks are transported via various carriers, such as the so called piccolo-bassoon transport vesicles (PTVs) (Zhai et al., 2001; Shapira et al., 2003), or synaptic vesicle protein transport vesicles (STVs) (Sabo et al., 2006). Synaptic vesicles themselves are probably composed of proteins coming from different transport organelles and are later fully assembled in the synaptic bouton 


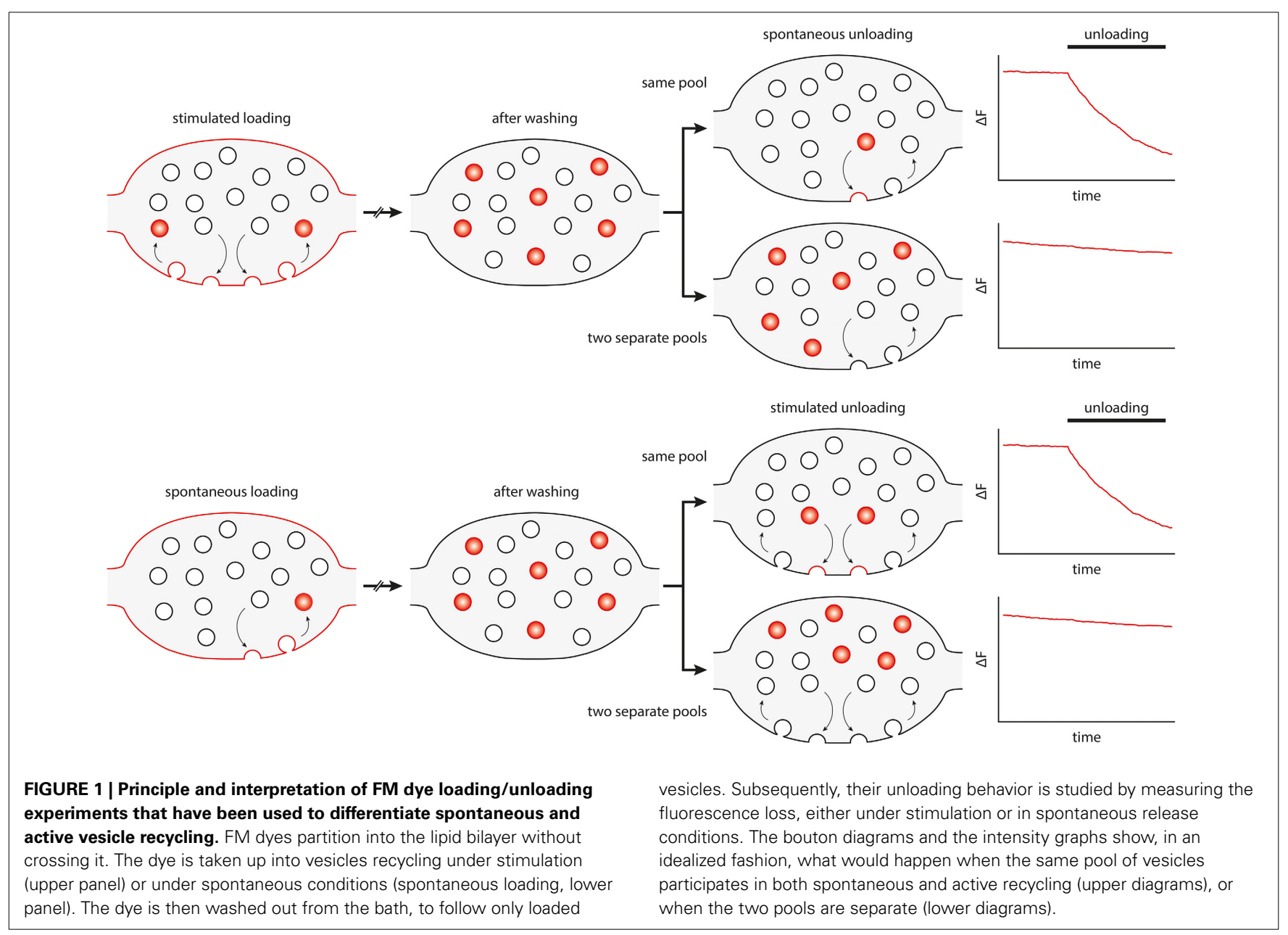

itself (see, for example, Rizzoli, 2014). Although various theories for synapse formation exist (see, for example, Scheiffele, 2003; McAllister, 2007), presynaptic STV clustering and release of neurotransmitter are essential, and may even predate the assembly of most other elements of the synapse (Sabo et al., 2006; see also Kaeser and Regehr, 2014).

Since the highly specific machinery of the active zone and bona fide synaptic vesicles are still missing from the to-be synapse, both neurotransmitter release and building block delivery must be ensured by CRVs. Such organelles are known from all cell types, where they typically participate in the early (sorting) endosome pathway. They have been described in nascent synapses as a heterogeneous population of dense-core, tubulovesicular, and pleomorphic vesicles, ranging in size up to $\sim 80 \mathrm{~nm}$ (Ahmari et al., 2000; Zhai et al., 2001; Ziv and Garner, 2004). This view is consistent with the observation that spontaneous neurotransmitter release is especially prevalent at developing synapses, where it is largely independent of stimulation (Kraszewski et al., 1995; Coco et al., 1998) and accounts for up to $80 \%$ of all release (Andreae et al., 2012). It should be noted in this context that constitutive fusion of vesicles outside active zones, and even outside synapses, where it cannot be stimulated by $\mathrm{Ca}^{2+}$, is a common observation, especially in developing neurons (Hume et al., 1983; Young and Poo, 1983; Matteoli et al., 1992; Zakharenko et al., 1999; Sabo and
McAllister, 2003). Furthermore, spontaneous release and synapse formation are not impaired in knock-outs of synaptotagmin 1, the main $\mathrm{Ca}^{2+}$ sensor of synaptic vesicles responsive to stimulation (Geppert et al., 1994). Additionally, synapse formation is not impaired in Doc2a/b double knock-outs (Groffen et al., 2010). Thus, it is tempting to hypothesize that in developing synapses spontaneously fusing vesicles are not bona fide SRSVs, but CRVs. As the synapses become established, stimulated release becomes predominant, and spontaneous release is dampened, consistent with the reduced need to deliver fresh building blocks to the synapse (Andreae et al., 2012).

The nature of the CRVs is not yet fully clear. A recent study suggested that they contain some synaptic vesicle markers, such as synaptophysin and neurotransmitter transporters, but have significantly lower amounts of some other proteins, most significantly the calcium sensor synaptotagmin 1 , when compared to bona fide synaptic vesicles. At the same time, CRVs were enriched in proteins of endosomal and constitutive trafficking pathways, such as the SNAREs syntaxin 13 and VAMP4 (Revelo et al., 2014). There are at least three different possible explanations for this observation. First, these vesicles might represent an organelle that is, in terms of biogenesis, completely separate from bona fide synaptic vesicles, and is involved in, for example, delivery of membrane to the synaptic bouton (unlikely, since these vesicles do 
contain synaptic vesicle markers). Second, CRVs might represent "rejects" from the synaptic vesicle biogenesis pathway. It is conceivable that biogenesis will not be successful for each and every synaptic vesicle, especially considering the complexity of the trafficking and final assembly steps involved in synaptic vesicle biogenesis (Bonanomi et al., 2006; Rizzoli, 2014). The CRVs might be faulty synaptic vesicles that have the ability to accumulate neurotransmitter (since otherwise there would not be any postsynaptic response to be observed), but without sufficient amounts of $\mathrm{Ca}^{2+}$ sensors for stimulated release, or inhibitors of spontaneous release (synaptotagmin 1, see above). Conversely, the insufficient clearing of constitutive and endosomal trafficking proteins from CRVs could thus enable them to release neurotransmitter independent of any stimulation, in a constitutive manner. Third, CRVs may not be "rejects" of the biogenesis pathway, but rather intermediates in the same pathway. The ability to release spontaneously might represent a transitory stage in the life cycle of a synaptic vesicle, during which it sheds unnecessary proteins, such as those of the constitutive pathway, and enriches synaptic vesicle proteins, via repeated fusion with the plasma membrane and subsequent recycling (Rizzoli, 2014). Thus, synaptic vesicles may fuse spontaneously early during their biogenesis, and stop doing so later, as they lose molecules of the constitutively trafficking pathway, and enrich bona fide synaptic vesicle molecules (Figure 2).

This third model also provides an explanation for the conflicting results obtained by several groups in the FM dye experiments relating to spontaneous release. If the CRV is an intermediate in the synaptic vesicle biogenesis pathway, it is probable that it still lacks some of the proteins necessary for stimulated release. Specifically, CRVs seem to contain lower levels of VAMP2 and synaptotagmin 1 (Revelo et al., 2014). This would render them less competent to respond to stimulation than bona fide synaptic vesicles, or even completely incompetent (see, for example, Rizzoli and Betz, 2002). Since a comparison of seven key studies on spontaneous release makes it evident that virtually identical experimental paradigms often yielded opposing results (Supplementary Table 1), we suggest the following explanation. It is well known that neuronal cultures of the same age can nevertheless have vastly different maturation rates, strongly dependent on, among other details, plating density (Fletcher et al., 1994; Biffi et al., 2013). This varies between laboratories, so despite the similar ages of the cultures, the different studies may have used cultures with different maturation states, and therefore with different rates of constitutive trafficking.

In line with this, studies suggesting one single pool are often based on tools specifically targeting synaptic vesicle proteins, such as VAMP2 or synaptotatmin 1 (see Supplementary Table 1) (Hua et al., 2010; Wilhelm et al., 2010). CRVs seem to contain less of these markers (Revelo et al., 2014), and therefore cannot be efficiently labeled this way, while FM dyes are non-specific and can label CRVs and SRSVs. The SRSVs would be releasable via stimulation, while the CRVs would not. Most studies discerning a separate spontaneous pool are based on FM dyes and find at least some unloading from this pool under stimulation (Sara et al., 2005; Mathew et al., 2008; Chung et al., 2010). The "spontaneous pool" labeled in FM-experiments was thus probably heterogeneously composed of CRVs and SRSVs. CRV prevalence decreases with neuron maturity (Andreae et al., 2012), preventing the detection of a separate spontaneous pool.

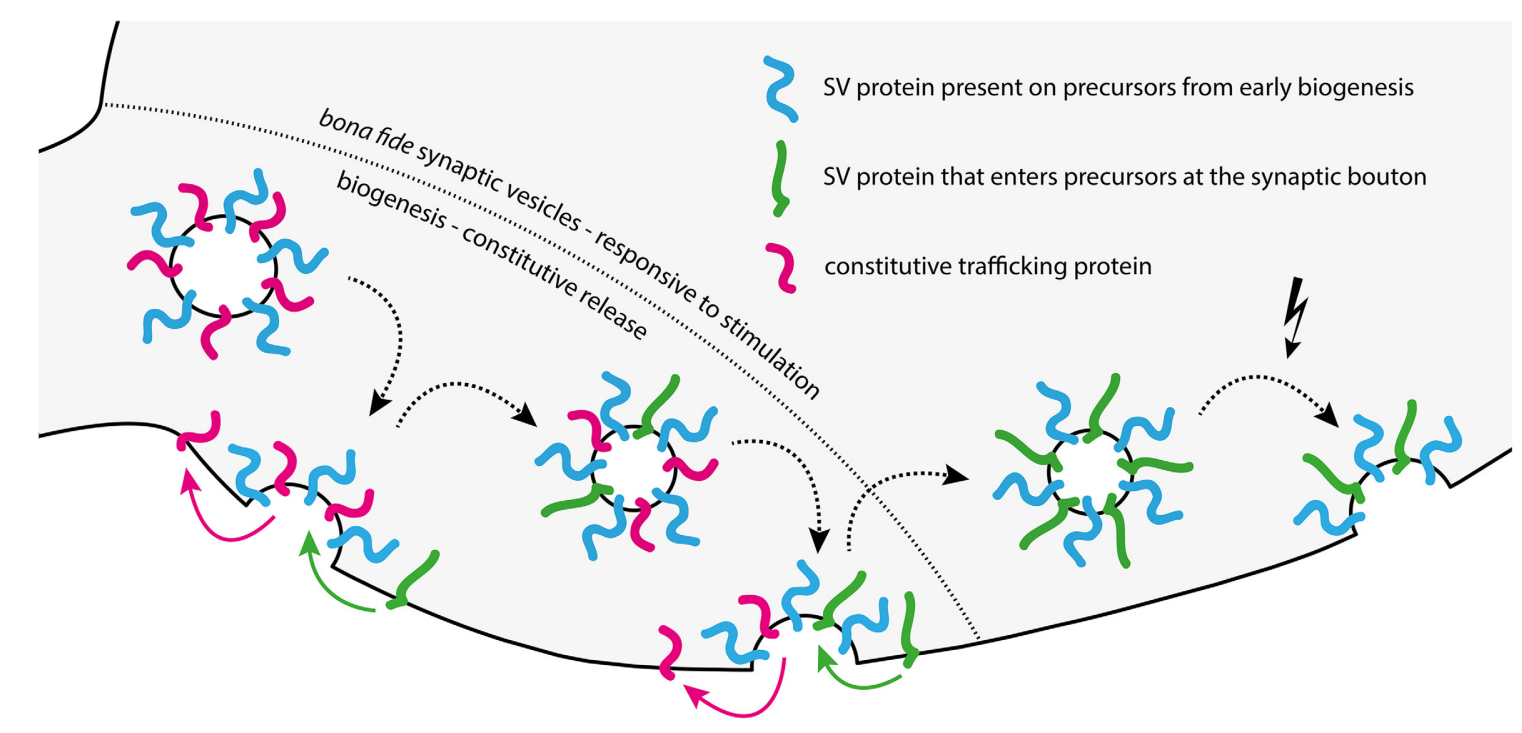

FIGURE 2 | Model of changes in synaptic vesicle composition and release behavior during biogenesis. Biogenesis from left to right: CRVs arriving at the synaptic bouton are molecularly "messy" synaptic vesicle precursors, having a different protein composition than bona fide synaptic vesicles. These precursors release spontaneously using constitutive trafficking proteins left over from biogenesis in the ER/Golgi system. They may lack the machinery necessary to sense and respond to stimulation. After several rounds of spontaneous release and recycling in the synapse, the emerging vesicle is cleared of most constitutive release proteins left over from biogenesis, and takes up additional synaptic vesicle (SV) proteins. With each recycling step during this phase, the vesicle becomes a bit less competent for spontaneous release, but a bit more competent for stimulated release. The end result is a fully formed, bona fide synaptic vesicle with little left over contamination (right of the dashed line). 


\section{MOLECULAR MARKERS OF THE SPONTANEOUSLY RECYCLING VESICLES}

Several recent studies found that vesicles containing the overexpressed SNAREs VAMP7 (Hua et al., 2011; Bal et al., 2013) or Vtila (Ramirez et al., 2012) behaved like CRVs, and were not responsive to stimulation. Since these molecules are classical constitutive trafficking markers, it is not surprising that they reach a type of vesicles that is not equivalent to synaptic vesicles. VAMP7 has been implicated in growth cone development and late endosome/lysosome trafficking (Wang and Tang, 2006; Burgo et al., 2012), while Vtila is known to participate in cis- and transGolgi trafficking (Fischer von Mollard and Stevens, 1998; Ganley et al., 2008). Additionally, a VAMP7/Vtila SNARE complex has been implicated in constitutive exocytosis and potassium channel trafficking to the plasma membrane, both in neuronal and non-neuronal cells (Flowerdew and Burgoyne, 2009).

The experiments in which overexpressed VAMP7 and Vtila reached spontaneously-, but not actively-releasing vesicles, have been interpreted as proof for their being the molecular mechanism that controls the reserve pool of synaptic vesicles (see Rizzoli and Betz, 2005, for a review on synaptic vesicle pools). This largely inert pool of vesicles, which does not recycle under physiological stimulation, was seen as the source of spontaneous release, via SNAREs such as VAMP7 (Fredj and Burrone, 2009; Hua et al., 2011; Bal et al., 2013) or Vtila (Ramirez et al., 2012). In view of more recent evidence, this is highly unlikely. Such molecules are present in mature synapses in very low copy numbers, two to three orders of magnitude lower than the exocytotic SNAREs (Takamori et al., 2006; Wilhelm et al., 2014). Such copy numbers would not allow them to be present in all reserve vesicles (Vtila averages at only $\sim 1$ copy per four vesicles in mature synapses; Wilhelm et al., 2014). Another argument against the hypothesis that VAMP7 and Vtila drive spontaneous release from the reserve pool is that there is very little spontaneous release in mature synaptic boutons (Andreae et al., 2012), although the reserve pool consists of at least $\sim 50 \%$ of all vesicles in mature synapses (Rizzoli, 2014). In contrast, the low copy numbers of SNAREs of the constitutive pathway agree with the hypothesis that spontaneous release is, at least in developing synapses, performed by constitutively recycling vesicles. Since such vesicles are not present in large numbers in mature synapses, neither should be their characteristic SNAREs.

\section{CONCLUSIONS: WHAT IS THE PURPOSE OF SPONTANEOUS RELEASE?}

We suggest that CRVs are, during the early development of the neuron, a pool of constitutively recycling membranes, which participate in the formation of synapses and synaptic vesicles. Putting this in perspective, a recent study determined that synapse development is perturbed by the abolishment of spontaneous, but not stimulated release (Choi et al., 2014). But even the established synapse is critically dependent on spontaneous neurotransmitter release (as recently reviewed by Andreae and Burrone, 2014). Abolishing it will first induce a compensatory receptor synthesis in the postsynapse (Sutton et al., 2006), later a loss of postsynaptic glutamate receptors (Saitoe et al., 2001), and will ultimately result in dissolving the synapse, evidenced by the loss of the dendritic spine (McKinney et al., 1999). Whether these spontaneously releasing vesicles are still members of the CRV pathway, or whether they are mature SRSVs responding to spontaneous $\mathrm{Ca}^{2+}$ fluctuations, perhaps via Doc $2 \mathrm{~b}$, still remains to be determined.

\section{ACKNOWLEDGMENTS}

Sven Truckenbrodt is supported by an Excellence Stipend of the Göttingen Graduate School for Neurosciences, Biophysics, and Molecular Biosciences (GGNB).

\section{SUPPLEMENTARY MATERIAL}

The Supplementary Material for this article can be found online at: http://www.frontiersin.org/journal/10.3389/fncel.2014. 00409/abstract

\section{REFERENCES}

Ahmari, S. E., Buchanan, J., and Smith, S. J. (2000). Assembly of presynaptic active zones from cytoplasmic transport packets. Nat. Neurosci. 3, 445-451. doi: $10.1038 / 74814$

Andreae, L. C., and Burrone, J. (2014). The role of neuronal activity and transmitter release on synapse formation. Curr. Opin. Neurobiol. 27C, 47-52. doi: 10.1016/j.conb.2014.02.008

Andreae, L. C., Fredj, N. B., and Burrone, J. (2012). Independent vesicle pools underlie different modes of release during neuronal development. J. Neurosci. 32, 1867-1874. doi: 10.1523/JNEUROSCI.5181-11.2012

Bal, M., Leitz, J., Reese, A. L., Ramirez, D. M. O., Durakoglugil, M., Herz, J., et al. (2013). Reelin mobilizes a VAMP7-dependent synaptic vesicle pool and selectively augments spontaneous neurotransmission. Neuron $80,934-946$. doi: 10.1016/j.neuron.2013.08.024

Betz, W. J., and Henkel, A. W. (1994). Okadaic acid disrupts clusters of synaptic vesicles in frog motor nerve terminals. J. Cell Biol. 124, 843-854. doi: 10.1083/jcb.124.5.843

Biffi, E., Regalia, G., Menegon, A., Ferrigno, G., and Pedrocchi, A. (2013). The influence of neuronal density and maturation on network activity of hippocampal cell cultures: a methodological study. PLOS ONE 8:e83899. doi: 10.1371/journal.pone.0083899

Bonanomi, D., Benfenati, F., and Valtorta, F. (2006). Protein sorting in the synaptic vesicle life cycle. Prog. Neurobiol. 80, 177-217. doi: 10.1016/j.pneurobio.2006.09.002

Burgo, A., Proux-Gillardeaux, V., Sotirakis, E., Bun, P., Casano, A., Verraes, A., et al. (2012). A molecular network for the transport of the TIVAMP/VAMP7 vesicles from cell center to periphery. Dev. Cell 23, 166-180. doi: 10.1016/j.devcel.2012.04.019

Ceccarelli, B., Hurlbut, W. P., and Mauro, A. (1973). Turnover of transmitter and synaptic vesicles at the frog neuromuscular junction. J. Cell Biol. 57, 499-524. doi: $10.1083 /$ jcb.57.2.499

Ceccarelli, B., Hurlbut, W. P., and Mauro, A. (1972). Depletion of vesicles from frog neuromuscular junctions by prolonged tetanic stimulation. J. Cell Biol. 54, 30-38. doi: 10.1083/jcb.54.1.30

Choi, B. J., Imlach, W. L., Jiao, W., Wolfram, V., Wu, Y., Grbic, M., et al. (2014). Miniature neurotransmission regulates Drosophila synaptic structural maturation. Neuron 82, 618-634. doi: 10.1016/j.neuron.2014.03.012

Chung, C., Barylko, B., Leitz, J., Liu, X., and Kavalali, E. T. (2010). Acute dynamin inhibition dissects synaptic vesicle recycling pathways that drive spontaneous and evoked neurotransmission. J. Neurosci. 30, 1363-1376. doi: 10.1523/JNEUROSCI.3427-09.2010

Coco, S., Verderio, C., De Camilli, P., and Matteoli, M. (1998). Calcium dependence of synaptic vesicle recycling before and after synaptogenesis. J. Neurochem. 71, 1987-1992. doi: 10.1046/j.1471-4159.1998.71051987.x

Del Castillo, J., and Katz, B. (1954). Quantal components of the end-plate potential. J. Physiol. 124, 560-573.

Fatt, B. Y. P., and Katz, B. (1950). Some observations on biological noise. Nature 166, 597-598. doi: 10.1038/166597a0

Fatt, B. Y. P., and Katz, B. (1952). Spontaneous subthreshold activity at motor nerve endings. J. Physiol. 117, 109-128. 
Fischer von Mollard, G., and Stevens, T. H. (1998). A human homolog can functionally replace the yeast vesicle-associated SNARE Vtilp in two vesicle transport pathways. J. Biol. Chem. 273, 2624-2630. doi: 10.1074/jbc.273.5.2624

Fletcher, L., De Camilli, P., and Banker, G. (1994). Synaptogenesis in hippocampal cultures: evidence indicating that axons and dendrites become competent to form synapses at different stages of neuronal development. J. Neurosci. 14, 6695-6706.

Flowerdew, S. E., and Burgoyne, R. D. (2009). A VAMP7/Vtila SNARE complex distinguishes a non-conventional traffic route to the cell surface used by KChIP1 and Kv4 potassium channels. Biochem. J. 418, 529-540. doi: 10.1042/BJ20081736

Fredj, N. B., and Burrone, J. (2009). A resting pool of vesicles is responsible for spontaneous vesicle fusion at the synapse. Nat. Neurosci. 12, 751-758. doi: $10.1038 / \mathrm{nn} .2317$

Ganley, I. G., Espinosa, E., and Pfeffer, S. R. (2008). A syntaxin 10-SNARE complex distinguishes two distinct transport routes from endosomes to the trans-Golgi in human cells. J. Cell Biol. 180, 159-172. doi: 10.1083/jcb.200707136

Geppert, M., Goda, Y., Hammer, R. E., Li, C., Rosahl, T. W., Stevens, C. F., et al. (1994). Synaptotagmin I: a major Ca2+ sensor for transmitter release at a central synapse. Cell 79, 717-727. doi: 10.1016/0092-8674(94)90556-8

Groemer, T. W., and Klingauf, J. (2007). Synaptic vesicles recycling spontaneously and during activity belong to the same vesicle pool. Nat. Neurosci. 10, 145-147. doi: 10.1038/nn1831

Groffen, A. J., Friedrich, R., Brian, E. C., Ashery, U., and Verhage, M. (2006). DOC2A and DOC2B are sensors for neuronal activity with unique calcium-dependent and kinetic properties. J. Neurochem. 97, 818-833. doi: 10.1111/j.1471-4159.2006.03755.x

Groffen, A. J., Martens, S., Díez Arazola, R., Cornelisse, L. N., Lozovaya, N., de Jong, A. P. H., et al. (2010). Doc2b is a high-affinity Ca2+ sensor for spontaneous neurotransmitter release. Science 327, 1614-1618. doi: 10.1126/science. 1183765

Heuser, J., and Miledi, R. (1971). Effect of lanthanum ions on function and structure of frog neuromuscular junctions. Proc. R. Soc. Lond. B Biol. Sci. 179, 247-260. doi: 10.1098/rspb.1971.0096

Hua, Y., Sinha, R., Martineau, M., Kahms, M., and Klingauf, J. (2010). A common origin of synaptic vesicles undergoing evoked and spontaneous fusion. Nat. Neurosci. 13, 1451-1453. doi: 10.1038/nn.2695

Hua, Z., Leal-Ortiz, S., Foss, S. M., Waites, C. L., Garner, C. C., Voglmaier, S. M., et al. (2011). v-SNARE composition distinguishes synaptic vesicle pools. Neuron 71, 474-487. doi: 10.1016/j.neuron.2011.06.010

Hume, R. I., Role, L. W., and Fischbach, G. D. (1983). Acetylcholine release from growth cones detected with patches of acetylcholine receptor-rich membranes. Nature 305, 632-634. doi: 10.1038/305632a0

Jahn, R., and Fasshauer, D. (2012). Molecular machines governing exocytosis of synaptic vesicles. Nature 490, 201-207. doi: 10.1038/nature11320

Kaeser, P. S., and Regehr, W. G. (2014). Molecular mechanisms for synchronous, asynchronous, and spontaneous neurotransmitter release. Annu. Rev. Physiol. 76, 333-363. doi: 10.1146/annurev-physiol-021113-170338

Kraszewski, K., Mundigl, O., Daniell, L., Verderio, C., Matteoli, M., and De Camilli, P. (1995). Synaptic vesicle dynamics in living cultured hippocampal neurons visualized with CY3-conjugated antibodies directed against the lumenal domain of synaptotagmin. J. Neurosci. 15, 4328-4342.

Littleton, J. T., Stern, M., Schuize, K., Perin, M., and Bellen, H. J. (1993). Mutational analysis of Drosophila synaptotagmin demonstrates its essential role in Ca2+activated neurotransmitter release. Cell 74, 1125-1134.

Mathew, S. S., Pozzo-Miller, L., and Hablitz, J. J. (2008). Kainate modulates presynaptic GABA release from two vesicle pools. J. Neurosci. 28, 725-731. doi: 10.1523/JNEUROSCI.3625-07.2008

Matteoli, M., Takei, K., Perin, M. S., Südhof, T. C., and De Camilli, P. (1992). Exoendocytotic recycling of synaptic vesicles in developing processes of cultured hippocampal neurons. J. Cell Biol. 117, 849-861. doi: 10.1083/jcb.117.4.849

McAllister, A. K. (2007). Dynamic aspects of synapse formation. Annu. Rev. Neurosci. 30, 425-450. doi: 10.1146/annurev.neuro.29.051605.112830

McKinney, R. A., Capogna, M., Dürr, R., Gähwiler, B. H., and Thompson, S. M. (1999). Miniature synaptic events maintain dendritic spines via AMPA receptor activation. Nat. Neurosci. 2, 44-49. doi: 10.1038/4548

Pang, Z. P., Bacaj, T., Yang, X., Zhou, P., Xu, W., and Südhof, T. C. (2011). Doc2 supports spontaneous synaptic transmission by a $\mathrm{Ca}(2+)$-independent mechanism. Neuron 70, 244-251. doi: 10.1016/j.neuron.2011.03.011
Ramirez, D. M. O., and Kavalali, E. T. (2011). Differential regulation of spontaneous and evoked neurotransmitter release at central synapses. Curr. Opin. Neurobiol. 21, 275-282. doi: 10.1016/j.conb.2011.01.007

Ramirez, D. M. O., Khvotchev, M., Trauterman, B., and Kavalali, E. T. (2012). Vtila identifies a vesicle pool that preferentially recycles at rest and maintains spontaneous neurotransmission. Neuron 73, 121-134. doi: 10.1016/j.neuron.2011.10.034

Revelo, N. H., Kamin, D., Truckenbrodt, S., Wong, A. B., Reuter-Jessen, K., Reisinger, E., et al. (2014). A new probe for super-resolution imaging of membranes elucidates trafficking pathways. J. Cell Biol. 205, 591-606. doi: $10.1083 /$ jcb. 201402066

Rizzoli, S. O. (2014). Synaptic vesicle recycling: steps and principles. EMBO J. 33, 788-822. doi: 10.1002/embj.201386357

Rizzoli, S. O., and Betz, W. J. (2002). Effects of 2-(4-morpholinyl)-8-phenyl-4H1-benzopyran-4-one on synaptic vesicle cycling at the frog neuromuscular junction. J. Neurosci. 22, 10680-10689.

Rizzoli, S. O., and Betz, W. J. (2005). Synaptic vesicle pools. Nat. Rev. Neurosci. 6, 57-69. doi: 10.1038/nrn1583

Rosenmund, C., and Stevens, C. F. (1996). Definition of the readily releasable pool of vesicles at hippocampal synapses. Neuron 16, 1197-1207. doi: 10.1016/S08966273(00)80146-4

Sabo, S. L., and McAllister, A. K. (2003). Mobility and cycling of synaptic protein-containing vesicles in axonal growth cone filopodia. Nat. Neurosci. 6, 1264-1269. doi: 10.1038/nn1149

Sabo, S. L., Gomes, R. A., and McAllister, A. K. (2006). Formation of presynaptic terminals at predefined sites along axons. J. Neurosci. 26, 10813-10825. doi: 10.1523/JNEUROSCI.2052-06.2006

Saitoe, M., Schwarz, T. L., Umbach, J. A., Gundersen, C. B., and Kidokoro, Y. (2001). Absence of junctional glutamate receptor clusters in Drosophila mutants lacking spontaneous transmitter release. Science 293, 514-517. doi: 10.1126/science. 1061270

Sara, Y., Virmani, T., Deák, F., Liu, X., and Kavalali, E. T. (2005). An isolated pool of vesicles recycles at rest and drives spontaneous neurotransmission. Neuron 45, 563-573. doi: 10.1016/j.neuron.2004.12.056

Scheiffele, P. (2003). Cell-cell signaling during synapse formation in the CNS. Annu. Rev. Neurosci. 26, 485-508. doi: 10.1146/annurev.neuro.26.043002. 094940

Shapira, M., Zhai, R. G., Dresbach, T., Bresler, T., Torres, V. I., Gundelfinger, E. D., et al. (2003). Unitary assembly of presynaptic active zones from Piccolo-Bassoon transport vesicles. Neuron 38, 237-252. doi: 10.1016/S0896-6273(03)00207-1

Südhof, T. C. (2004). The synaptic vesicle cycle. Annu. Rev. Neurosci. 27, 509-547. doi: 10.1146/annurev.neuro.26.041002.131412

Südhof, T. C. (2013). Neurotransmitter release: the last millisecond in the life of a synaptic vesicle. Neuron 80, 675-690. doi: 10.1016/j.neuron.2013.10.022

Sutton, M. A., Ito, H. T., Cressy, P., Kempf, C., Woo, J. C., and Schuman, E. M. (2006). Miniature neurotransmission stabilizes synaptic function via tonic suppression of local dendritic protein synthesis. Cell 125, 785-799. doi: 10.1016/j.cell.2006.03.040

Takamori, S., Holt, M., Stenius, K., Lemke, E. A., Grønborg, M., Riedel, D., et al. (2006). Molecular anatomy of a trafficking organelle. Cell 127, 831-846. doi: 10.1016/j.cell.2006.10.030

Walter, A. M., Groffen, A. J., Sørensen, J. B., and Verhage, M. (2011). Multiple Ca2+ sensors in secretion: teammates, competitors or autocrats? Trends Neurosci. 34, 487-497. doi: 10.1016/j.tins.2011.07.003

Wang, Y., and Tang, B. L. (2006). SNAREs in neurons-beyond synaptic vesicle exocytosis (Review). Mol. Membr. Biol. 23, 377-384. doi: 10.1080/0968786060 0776734

Wilhelm, B. G., Groemer, T. W., and Rizzoli, S. O. (2010). The same synaptic vesicles drive active and spontaneous release. Nat. Neurosci. 13, 1454-1456. doi: 10.1038/nn.2690

Wilhelm, B. G., Mandad, S., Truckenbrodt, S., Krohnert, K., Schafer, C., Rammner, B., et al. (2014). Composition of isolated synaptic boutons reveals the amounts of vesicle trafficking proteins. Science 344, 1023-1028. doi: 10.1126/science. 1252884

Xu, J., Pang, Z. P., Shin, O.-H., and Südhof, T. C. (2009). Synaptotagmin-1 functions as a Ca2+ sensor for spontaneous release. Nat. Neurosci. 12, 759-766. doi: $10.1038 / \mathrm{nn} .2320$

Young, S. H., and Poo, M. (1983). Spontaneous release of transmitter from growth cones of embryonic neurones. Nature 305, 634-637. doi: 10.1038/305634a0 
Zakharenko, S., Chang, S., O'Donoghue, M., and Popo, S. V. (1999). Neurotransmitter sectretion along growing nerve processes: comparison with synaptic vesicle exocytosis. J. Cell Biol. 144, 507-518.

Zefirov, A. L., Abdrakhmanov, M. M., Mukhamedyarov, M. A., and Grigoryev, P. N. (2006). The role of extracellular calcium in exo- and endocytosis of synaptic vesicles at the frog motor nerve terminals. Neuroscience 143, 905-910. doi: 10.1016/j.neuroscience.2006.08.025

Zhai, R. G., Vardinon-Friedman, H., Cases-Langhoff, C., Becker, B., Gundelfinger, E. D., Ziv, N. E., et al. (2001). Assembling the presynaptic active zone: a characterization of an active one precursor vesicle. Neuron 29, 131-143. doi: 10.1016/S0896-6273(01)00185-4

Ziv, N. E., and Garner, C. C. (2004). Cellular and molecular mechanisms of presynaptic assembly. Nat. Rev. Neurosci. 5, 385-399. doi: 10.1038/ nrn1370
Conflict of Interest Statement: The authors declare that the research was conducted in the absence of any commercial or financial relationships that could be construed as a potential conflict of interest.

Received: 24 September 2014; accepted: 11 November 2014; published online: 08 December 2014.

Citation: Truckenbrodt $S$ and Rizzoli SO (2014) Spontaneous vesicle recycling in the synaptic bouton. Front. Cell. Neurosci. 8:409. doi: 10.3389/fncel.2014.00409

This article was submitted to the journal Frontiers in Cellular Neuroscience.

Copyright $\odot 2014$ Truckenbrodt and Rizzoli. This is an open-access article distributed under the terms of the Creative Commons Attribution License (CC BY). The use, distribution or reproduction in other forums is permitted, provided the original author(s) or licensor are credited and that the original publication in this journal is cited, in accordance with accepted academic practice. No use, distribution or reproduction is permitted which does not comply with these terms. 